\title{
Managing anti-consumption in an excessive drinking culture ${ }^{i}$
}

\author{
Maria G. Piacentini *, Emma N. Banister ${ }^{1}$ \\ Department of Marketing, Lancaster University Management School, Lancaster LA1 4YX, United Kingdom
}

Received 1 June 2007; received in revised form 1 November 2007; accepted 1 January 2008

\begin{abstract}
A major contemporary challenge facing governments and health professionals is that of promoting sustainable and healthy approaches to alcohol consumption in a context where excessive alcohol consumption is the dominant trend [Plant M., Plant M., Binge Britain: the need for courage. Alcoholis 2006; 25, 3: 1.]. This article reports the results of a qualitative study examining the experiences of Higher Education students in the United Kingdom who are identifiable as anti-consumers because of their opposition to the alcohol norms that predominate. The article focuses on how these students deal with the challenges and consequences that can arise from resisting the prevailing norms and practices. This article demonstrates that existing frameworks and categorizations in the contexts of anti-consumption, product and brand avoidance and coping are capable of providing useful theoretical tools for the examination of anti-consumption within the social marketing context. The article identifies some of the implicit tensions of being an anti-consumer in an environment of excessive consumption and provides examples of how consumers seek to manage these tensions. The use of the above theoretical perspectives can usefully inform policy that aims to promote sensible drinking among young people and students in particular.
\end{abstract}

(c) 2008 Elsevier Inc. All rights reserved.

Keywords: Anti-consumption; Alcohol consumption; Social marketing; Coping

\section{Introduction}

A major contemporary challenge facing governments and health professionals is that of promoting sustainable and healthy approaches to alcohol consumption in a context where excessive alcohol consumption is the dominant trend (Plant and Plant, 2006). The prevalence of excessive alcohol consumption-or binge drinking - is an issue within student populations globally, and particularly within the UK (Banister and Piacentini, 2006; D’Alessio et al., 2006; Kuntsche et al., 2004; Wechsler et al., 2002). Understanding the prevalence of binge drinking within student populations is useful for anyone involved in policy and

\footnotetext{
The authors thank two anonymous reviewers and the editors of the special issue who provided detailed and useful comments on earlier versions of this paper. The authors also thank Isabelle Szmigin and Bob Kemp for their useful comments and insights. The authors are extremely grateful towards the Lancaster University pump-priming fund for providing this study with funding.

* Corresponding author. Tel.: +44 1524593 906; fax: +44 1524593928.

E-mail addresses: m.piacentini@lancaster.ac.uk (M.G. Piacentini), e.banister@lancaster.ac.uk (E.N. Banister).

${ }^{1}$ Tel.: +44 1524593 299; fax: +44 1524593928.
}

professional work in the area. However, another parallel population whose study offers a useful and interesting insight into the phenomenon of excessive alcohol consumption is the nondrinking student population, in particular those students who actively resist the prevailing culture. Scholars define anti-consumption as behavior that is against consumption (Craig-Lees, 2006; Lee et al., 2009b-this issue; Zavestoski, 2002) and, in this study, anti-consumption refers to people who opt out of the dominant culture of excessive alcohol consumption. This article reports the results of a qualitative study examining the experiences of Higher Education students in the United Kingdom who are identifiable as anti-consumers, because of their opposition to the alcohol norms that predominate. The article focuses on how such students deal with the challenges and consequences that can arise from resisting the prevailing norms and practices.

\section{Literature}

Many studies consider the circumstances around excessive alcohol consumption, in particular focusing on the question 
of motivation. A central argument is that two distinct sets of motivations exist. First, alcohol facilitates socialization, particularly for young people (Darian, 1993; Liu and Kaplan, 1996; Pavis et al., 1997), with the ritualistic aspects of alcohol consumption contributing to these social effects (Beccaria and Sande, 2003). More recent research focuses on understanding the social worlds of young people and students and the role that alcohol plays in constructing these social worlds (see for example Banister and Piacentini, 2006; Measham, 2004; Piacentini and Banister, 2006; Treise et al., 1997). The second set of motivations driving alcohol consumption relate to the personal benefits associated with drinking such as asserting gender identity, mood alteration, coping with personal problems, dealing with stress and relieving boredom (Darian, 1993; Liu and Kaplan, 1996; Pavis et al., 1997; Thom and Francome, 2001).

These previous studies focus on the benefits associated with alcohol and help explain consumers' motivations to consume excessive amounts of alcohol. However, fewer studies document the experiences of young people who choose to opt out of the excessive drinking culture. One exception is Nairn, Higgins, Thompson, Anderson, and Fu (2006) who examine high school students. In their study, they describe non-participants in the alcohol culture as having alternative subject positions, that is, alternative to the prevailing drinking culture (Nairn et al., 2006). Non-participants could include those who avoid alcohol altogether, but also infrequent (Nairn et al., 2006), light (Banister et al., 2005) or 'responsible' (Darian, 1993) drinkers.

Alcohol plays a central role in the social lives of students (Gill, 2002; Gofton, 1990; Webb et al., 1996), but this presents problems for students who choose to resist the pressures to conform and participate in the prevailing alcohol culture (Piacentini and Banister, 2006). For instance non-involvement in the alcohol culture may prevent full engagement with student social life (Nairn et al., 2006) providing a source of tension for those choosing not to consume or to consume comparatively little alcohol. To develop understanding of the phenomenon of antiexcessive consumption, this article explores other aspects of anti-consumption behavior (in particular voluntary simplicity and brand avoidance) to illuminate some of the motives, challenges and consequences of anti-consumption in the context of students' alcohol consumption.

\subsection{Voluntary simplicity}

Voluntary simplifiers make informed decisions to restrict their consumption. However, while voluntary simplifiers may be opposed to elements of mainstream consumer society, as Shaw and Newholm (2002) argue (drawing on Etzioni, 1998), voluntary simplifiers live "within consumer capitalism, not in complete opposition to it" (p.170). Voluntary simplifiers do not seek to exit the market, as in the manner of the Burning Man festival participants (described by Kozinets, 2002), but aim to reduce the various excesses of being a consumer. Despite being an anticonsumption behavior, voluntary simplicity perhaps more accurately refers to reformulating consumption choices - for example, reducing consumption in many areas but also targeting other consumption in favor of those products and practices that are deemed more acceptable or appropriate (Craig-Lees and Hill, 2002; Shaw and Newholm, 2002). Like many voluntary simplifiers, students who decide against excessively consuming alcohol have no choice but to operate within the wider student body; they cannot exist outside the (alcohol dominated) student culture, despite consuming in ways that are divergent to the prevailing norm.

A further parallel between voluntary simplicity and anticonsumption of alcohol is that both voluntary simplifiers and anticonsumers of alcohol exhibit heterogeneity of behaviors and values. Wachtel (1996, p. 225) describe voluntary simplicity as "a complex set of attitudes, inclinations and changes in goals and lifestyles". Voluntary simplicity can involve a wide spectrum of practices and values with considerable diversity in the ways that consumers put beliefs into practice. Shaw and Newholm (2002) situate voluntary consumers on a continuum from consumers who fully embrace ideas about reducing consumption (largely driven by ethical concerns to own and use fewer consumer goods) to consumers who simply refine their consumption towards ethical standards. The latter set of consumers continues to have similar levels of consumption, but they consume differently, and in line with some of their ethical concerns. Similarly Huneke (2005) distinguishes 'highly committed' from 'less committed' simplifiers who "are likely to simplify in ways that are not overly disruptive to their lives" (p.546). Student anti-consumers of alcohol are also likely to show similar variation, and to incorporate a range of rationales and behaviors, that may cause consumers to respond in a variety of ways.

\subsection{Brand avoidance}

Another relevant area of research is brand avoidance (Lee and Conroy, 2005; Lee et al., 2009a-this issue). Lee and colleagues describe a set of brand avoidance categories that can theoretically extend beyond individual brands to the entire product category of alcohol, and to the excessive consumption of products within this product category.

The first category is experiential avoidance, where consumers avoid a brand following a bad experience. This category is clearly transferable to the alcohol consumption context. A bad experience (e.g. an accident or a bad hangover) could result in the general avoidance of alcohol or a more specific avoidance of particular products (e.g. whisky) or product types (e.g. spirits) associated with the negative experience. A second category, identity avoidance, is also useful. Here consumers avoid brands because they do not identify with the brand or, in this context, the product category. This lack of identification may reflect negative possible selves (Banister and Hogg, 2004; Hogg and Banister, 2001) informed by negative stereotypes (as discussed in Dalli et al., 2005). A final useful category is moral avoidance, which includes attitudes and behaviors questioning the dominant forces or the prevalent norms of consumption. This category of avoidance overlaps with some of the ideological motivations for voluntary simplicity (McDonald et al., 2006) and in the alcohol context could relate to a more general anti-alcohol sentiment, possibly originating from ethical or religious beliefs. 
The consequences of the decision to opt out of the dominant excessive drinking culture are a key focus of this article. If studenthood represents an opportunity to have fun and socialize, a liminal stage between childhood and adulthood (Banister and Piacentini, 2008), then the decision to opt out of the drinking culture could involve challenging consequences, particularly the potential contradiction between the non-drinking self and the social student self. Coping theory provides one way of examining the ways that non-drinkers manage these challenges and tensions.

\subsection{Coping theory}

Coping strategies describe the ways that individuals respond to stress, and typically aim at either alleviating emotional (and cognitive) responses or are directed towards solving associated problems in some way (Folkman, 1986; Godwin et al., 1995; Lazarus, 1991). Lazarus and Folkman (1984) identify three main coping strategies: problem-focused coping (taking action such as planful problem solving, confronting the situation, accepting responsibility); emotion-focused coping (managing emotional aspects of situations, such as by denying a threat exists, by distancing oneself from the threat or avoiding thinking about the threat); and cultivating, seeking and using social support (offering emotional, tangible or informational support). Penaloza and Price (1993) identify a further coping category of resistance. Resistance is the way that individuals and groups "practice a strategy of appropriation in response to structures of domination" (Poster, 1992, p94), which is relevant in this context where the focus is on consumers who resist their surrounding dominant consumer culture. The various strategies that consumers adopt to cope with the consequences of their decision not to drink are likely to provide deeper insights into the lived experience of practicing anti-consumption.

Drawing on the literature relating to the practice of voluntary simplification, the authors position the variants of alcohol anti-consumption on a continuum ranging from absolute nonconsumption through to light consumption. The position anticonsumers occupy in behavioral terms is likely to relate to their rationales for adopting this position, and the experiences they have as anti-consumers. To forge a clearer understanding of the anti-consumption of alcohol, this article aims to examine the nature of anti-consumption behavior in the context of alcohol consumption. Specifically, this article explores the triggers for behavior, and some of the ways that students deal with the challenges and consequences arising from resisting the prevailing norms and practices of the alcohol dominated culture.

\section{Methodology}

Data collection was via one-to-one in-depth interviews as part of a larger study of students and their alcohol consumption. The study recruited undergraduate student participants from one research site, a university in the North West of England, via an advertisement posted around campus and placed on course websites. This article focuses on individuals who identify themselves as "not drinking alcohol". The researchers originally anticipated that not drinking alcohol would mean just that. However, participants interpreted not drinking as a continuum of behavior from absolute non-consumption through to light or occasional consumption, perceiving not drinking in comparative terms relative to the dominant norms within the student culture. All participants, regardless of alcohol consumption levels, saw themselves as operating outside the norms of consumption, supporting the notion that there are distinct parallels with voluntary simplifiers.

The nine participants (four males, five females) come from a variety of socio-cultural backgrounds. The continuum of behaviors they identify as reflecting non-consumption indicates the potential for behavioral overlap with those students who identify themselves as drinkers. The participants' reported behaviors fit well with their self-definition as non-drinkers, if this term includes light and occasional drinking as well as clear abstinence. Table 1 demonstrates this continuum of behaviors, ranging from abstinence (Lena, Jack, Bob), to occasional consumption (Gayle, Kelly, Alice), to light regular consumption (Fifi, Pete, Andy).

The researchers used a semi-structured interview guide in order to ensure the two interviewers covered similar topics, but followed a phenomenologically informed approach (Thompson et al., 1989); the researchers did not rely on the guide, but rather, let the participants' stories unfold in a natural conversational way. Each interview lasted between 45 and $89 \mathrm{~min}$, and all were digitally recorded and transcribed.

Both authors undertook the analysis, first separately and independently, followed by a phase of sharing to explore alternative explanations. Transcript analysis consisted of reading and re-reading, noting patterns and themes in a search for "patterns and recurring organizations" (Wetherall et al., 1988, p.177), accompanied by a process of categorization, abstraction, comparison and integration (Spiggle, 1994). All participants' names have been changed for the purposes of this article.

\section{Findings}

\subsection{Antecedents of anti-excessive consumption}

Four broad categories of antecedents leading to anti-excessive consumption exist: (1) Personal experience of excessive alcohol consumption with severe consequences; (2) Close family experience of alcoholism; (3) Religious, political or cultural reasons; (4) General misgivings about alcohol. Table 1 details the antecedents as they apply to the study participants.

The first category overlaps with Lee et al.'s (2009a,b-this issue) experiential avoidance construct, where consumers avoid a brand or product following a bad experience. Jack provides an example of this trigger. Previously a regular heavy drinker, he describes his history of heavy drinking, which had featured some serious incidents involving alcohol. None, however, had triggered a change in his behavior. This change did not happen until he started university, when Jack indulged in what he termed "two weeks of excessive drinking". Jack visited the campus nurse unit after feeling pains where a blood test revealed he had acute pancreatitis. Jack now abstains completely from alcohol 
Table 1

Participant information

\begin{tabular}{|c|c|c|c|c|}
\hline Name & Age, sex, nationality & Drinking profile & Antecedents & Coping strategies adopted \\
\hline Gayle & $\begin{array}{l}\text { 19, Female, } \\
\text { British }\end{array}$ & $\begin{array}{l}\text { Very occasionally drinks. } \\
\text { Previously a light drinker }\end{array}$ & $\begin{array}{l}\text { General misgivings } \\
\text { about alcohol }\end{array}$ & $\begin{array}{l}\text { Planful problem solving (assuming the role of driver and carer) } \\
\text { Distancing (dealing with social situations) }\end{array}$ \\
\hline Fifi & 20, Female, Chinese & $\begin{array}{l}\text { Light drinker, mainly } \\
\text { on cultural grounds }\end{array}$ & $\begin{array}{l}\text { Negative personal } \\
\text { experience }\end{array}$ & $\begin{array}{l}\text { Distancing (from bad experience around alcohol) } \\
\text { Seeking social support (seeking friendship from others who don't drink) }\end{array}$ \\
\hline Lena & 22, Female, Persian & $\begin{array}{l}\text { Non-drinker on religious } \\
\text { grounds (Baha'i) }\end{array}$ & $\begin{array}{l}\text { Religious, political, } \\
\text { cultural }\end{array}$ & $\begin{array}{l}\text { Resistance strategies (trying to subvert others' drinking behavior by, } \\
\text { for example, hiding their drinks) } \\
\text { Confrontive coping (sometimes questioning others' behavior) } \\
\text { Self control (despite finding others' drinking stressful, balances } \\
\text { stress against her desire to be non-judgmental so does not } \\
\text { always express her feelings about others' drinking) }\end{array}$ \\
\hline Alice & 21, Female, British & $\begin{array}{l}\text { Very occasionally drinks } \\
\text { (once per year) }\end{array}$ & $\begin{array}{l}\text { General misgivings } \\
\text { about alcohol }\end{array}$ & $\begin{array}{l}\text { Planful problem solving (participating in games as a non-drinker; } \\
\text { assuming responsible role) }\end{array}$ \\
\hline Pete & 21, Male, British & $\begin{array}{l}\text { Light drinker. } \\
\text { Previously a heavy drinker. }\end{array}$ & $\begin{array}{l}\text { General misgivings } \\
\text { about alcohol }\end{array}$ & $\begin{array}{l}\text { Planful problem solving (assumes driver and responsible person role) } \\
\text { Accepting responsibility (making significant changes to his behavior) } \\
\text { Escape-avoidance (dealing with drunken others in various contexts) } \\
\text { Positive re-appraisal (focus on academic and financial benefits of } \\
\text { reducing alcohol intake) }\end{array}$ \\
\hline Kelly & 21, Female, British & $\begin{array}{l}\text { Very occasionally drinks, } \\
\text { never drank excessively. }\end{array}$ & $\begin{array}{l}\text { Family experience } \\
\text { of alcoholism }\end{array}$ & $\begin{array}{l}\text { Planful problem solving (assumes responsible person role) } \\
\text { Self control (does find others' drinking stressful at times, but rarely } \\
\text { expresses her feelings about others' drinking) }\end{array}$ \\
\hline Andy & 21, Male, British & $\begin{array}{l}\text { Light drinker. Previously } \\
\text { a heavy drinker, reduced } \\
\text { significantly at } 18 .\end{array}$ & $\begin{array}{l}\text { Negative personal } \\
\text { experience }\end{array}$ & $\begin{array}{l}\text { Planful problem solving (assumes driver role) } \\
\text { Accepted responsibility (reflecting on his negative personal } \\
\text { experience, he accepts responsibility and changes his behavior) } \\
\text { Escape-avoidance (dealing with his relapse during } \\
\text { Freshers' Week social event) }\end{array}$ \\
\hline Bob & 20, Male, British & $\begin{array}{l}\text { Non-drinker. Previously a } \\
\text { heavy drinker, stopped at } 16 .\end{array}$ & $\begin{array}{l}\text { Family experience } \\
\text { of alcoholism }\end{array}$ & $\begin{array}{l}\text { Planful problem solving (preparing for transition to university) } \\
\text { Self control (does not discuss other's drinking, but represents } \\
\text { a source of stress to him) } \\
\text { Positive re-appraisal (focusing on the benefits) }\end{array}$ \\
\hline
\end{tabular}

consumption because of the severity of this incident, and the absolute warning he received from health professionals against drinking alcohol. He has had one or two episodes where he has unwittingly consumed alcohol (in foods), and the consequences have been severe (hospitalization).

The second category highlights a more specific form of experiential avoidance that stems from other people's negative experiences around alcohol (e.g. involving close family members, rather than the participant specifically). This vicarious experiential avoidance appears in Kelly's case. The death of Kelly's aunt was alcohol-related, and because of this direct experience, Kelly is adamant she will not participate in the dominant alcohol culture. She associates binge drinking among her peers with alcoholism.

Kelly: ...I don't have anything against people drinking it [alcohol] in moderation. But people my age don't seem to realize... I would call quite a few of my friends alcoholics, but if you ever said to them 'I think you behave like an alcoholic'... they just don't associate that with what they do at all.

Kelly's negative beliefs about alcohol are something she feels very strongly about ("I can't stand alcohol"), yet she sees herself as non-judgmental of others' drinking behavior ("I don't have anything against people drinking...in moderation"). Kelly's position causes her tension, which she manages through regulating her feelings to avoid risking jeopardizing friendships, an example of a self-control coping strategy (Lazarus and Folkman, 1984). The inherent contradiction in her narrative is rooted in the tensions that non-drinkers, who wish to participate in an alcohol-centered social culture, face.

The third category refers to an ideological basis for behavior, and shares characteristics with Lee et al.'s (2009a,b-this issue) moral avoidance category. Lena provides a good illustration of this category. She believes that drinking alcohol is not acceptable within her (Baha'i) religion. However, like Kelly, she balances this belief against a strong desire to be nonjudgmental of other people's lifestyle choices and values, which is also part of her religious belief system, again creating a personal tension.

Lena: I guess one of my main things would be not to judge people. I respect people for their choices, but it is almost instinctive to judge them for drinking alcohol... Sometimes I might not want to be around them.

Despite participating in some general student activities, Lena successfully carves out an alternative identity for herself at 
university, centered on socializing with other international students. Her social activities include meditation, trips to the cinema, gatherings in her room, as well as activities associated with the Baha'i society.

The fourth category reflects a lack of fit between the individual's current life stage and their perception of the culture of excessive alcohol consumption, sharing characteristics with Lee et al.'s (2009a,b-this issue) category of identity avoidance ("it's not for me"). For Pete, a final year student, excessive alcohol consumption is incompatible with his current life stage. This incompatibility is evident in the way he talks about the relationship between drinking alcohol, his academic studies and the potential impact on his employment chances.

Pete: I think I took the conscious decision because I'm coming into employment soon, and I just wanted to be more motivated and I find drinking and studying and all the other stuff not compatible... I find it more enjoyable to get up and go to the gym in the morning and only have a coke or something on a night out. I just feel a lot happier in general.

In contrast, Gayle describes stopping drinking during her first term at University, and describes her decision to stop drinking as a gradual process rather than a deliberate act.

Gayle: It's not a conscious decision. I'm not saying to myself I'm not going to drink. I don't have all these specific reasons why, it just happened to work out that way, I just don't see the point of it, like drink[ing] large quantities of drink.

Although Gayle does not accept or participate in this behavior, she does not adopt a moral position and this approach is typical of those in this category. Her position is closest to the identity avoidance category defined by Lee et al. (2009a,b-this issue), where she clearly expresses her avoidance self (Banister and Hogg, 2001) "all they do is go and get really drunk", from which she distances herself: "that's not me".

These categories are useful to bring some order to the data and to develop understanding of the triggers of anti-excessive consumption positions. However, some of these categories overlap. For example, although Fifi's approach to alcohol consumption is informed by her cultural upbringing (i.e. religious, political or cultural reasons), her specific trigger for change relates to a particular night out where she regretted consuming so much alcohol. Her main antecedent, therefore, exhibits more congruency with the first category of antecedents, that relating to personal experience of excessive alcohol consumption with severe consequences.

\subsection{Challenges and consequences}

Participants have made their decisions to be anti-consumers in the context of a culture of excessive alcohol consumption. As a result of this decision, they find their positions on alcohol consumption are ambivalent and at times difficult and challenging. The remaining analysis focuses on the nature of these challenges, and explores how participants resolve the tensions triggered by the interplay between internal (personal) and external (social) pressures.

\subsubsection{Managing new social situations}

New social situations can be stressful for non-drinkers. Participants use a variety of coping strategies to deal with these new situations, which suggests that this challenge is one of the most complex aspects of being a non-drinker. Some participants (Kelly, Andy) cope by participating in the alcohol-related social activities, albeit on their terms. For example, Andy, who formed his attitudes and views about alcohol before coming to university, describes his behavior on arrival at university as exceptional for him. Andy drank alcohol during Freshers' Week but quickly regretted this decision. Andy's attempt to rationalize his relapse provides useful contextual information about the social pressures to drink and the potential tensions that student anti-consumers of alcohol often experience.

Andy: It's definitely... a big thing as soon as you're there, as soon as you arrive, it's like 'oh there's a social in the bar tonight', so you don't have a choice... You're encouraged to get drunk I think... the way the socials are arranged, they're all arranged around drinking... so you can't really escape from it.

Andy adapts to the new situation, initially, by participating in the dominant culture. This period represents a temporary shortterm relapse from his anti-excessive consumption position and solves the immediate social problem, but then provides a source of tension for him. Andy adopts an escape-avoidance coping strategy by expressing regret at his behavior, while rationalizing his relapse in terms of the intense social pressure to conform and participate in the drinking culture. This rationalization helps him justify his relapse, but still maintain an anti-excessive consumption position.

Distancing is another form of emotion-focused strategy that participants draw on in social situations where they feel a pressure to participate in a particular way. Fifi describes similar situations, to Andy, where she "had to drink"; although she is uncomfortable with this pressure to consume alcohol, she copes by placing some distance between herself and the situation. She focuses on the normative pressures to drink in order to rationalize her behavior, saying: "you don't want to be different from them".

Other participants draw on problem-solving strategies (Lazarus, 1991). For example, Bob describes his preparations for the transition to university life, which demonstrate his acute awareness of the importance of alcohol in students' social lives. Bob describes forward planning to ensure he is socially competent; in the summer before starting university he went out socializing with friends, in order to develop the necessary skills to behave appropriately in social situations (yet without alcohol).

Bob: [In] Freshers' Week... I knew that I was going to have to go out and meet people... so [in]... the first couple of months before I came here, I decided to... start going out with my mates and just... give it a try... Because especially with the club scene, I'd never really given it a chance, I didn't really know from experience whether I liked it or not. I decided whilst I was still at home and while it was still the 
summer and all my best friends were back home from their universities you know, I'd be better off giving it a try with them before [going to university].

\subsubsection{Challenging the stereotype of the non-drinker}

Managing other peoples' expectations and assumptions about non-drinkers is a key concern for participants, and some describe purposefully exhibiting behaviors that challenge the stereotypical view of the non-drinker. Adopting these behaviors is a form of resistance strategy (Penaloza and Price, 1993) where participants aim to subvert others' expectations of them (based on their alcohol position), and to ensure these expectations do not extend into other aspects of their life. For example, Kelly emphasizes the extent to which she participates in social events, and the fact that her strong personality means others do not notice her non-drinking.

Kelly: It's funny that because I've been out on nights out where there's someone not drinking and everyone's shoving drinks their way more than me, they don't seem to notice that I don't drink. I think it's because I'm quite loud anyway and I'm quite silly anyway.

Kelly contrasts her personality with one of her friends, a Christian, who she describes as "a bit square" and "doesn't seem to have as good a time" when not drinking. Kelly's personality is a key factor that facilitates the smooth and mostly straightforward practice of anti-consumption. On the rare occasions when she does drink alcohol, such as special birthday celebrations, Kelly faces even more pressure to manage people's expectations, as shown in this comment about her 21 st birthday party:

Kelly: I get really easily tipsy, very easily tipsy, and they said I was quite loud at the dinner table but not like bleary. All my friends know that I don't really drink that much. I get a lot of comments like 'oh my God I'd love to see you wasted' or 'I've never seen you wasted'.

Participants also need to manage questions about their anticonsumption stance. Having a socially acceptable response is important, particularly for the male participants. Jack illustrates this point, apparently taking pride in his label as the "guy that obliterated his pancreas". This label provides him with status in the eyes of other drinkers, since they view him as a mature ex-drinker, with a story to tell, rather than a naïve nondrinker.

Jack: I usually just say 'my pancreas exploded' and that's about all there is to it really, so. And I usually get the sort of 'Oh God' reaction and all that... I tend to just take it with good humor you know, make a bit of a joke out of it rather than say 'yeah, it was horrible, it destroyed my life' or anything like that because it didn't.

The manner in which Jack handles questions about his anticonsumption position emphasizes the social performance aspects of not participating in excessive alcohol consumption. Although Jack has no choice but to be an anti-consumer, his past experiences with alcohol provide him with instant credibility, confounding the non-drinking stereotype: "I sort of established myself as being in excess of the drinking culture, which had a sort of coolness in itself I guess".

Participants, essentially, stage-manage their involvement and performance in the alcohol drinking culture, illustrating the extent to which their non-consumption of alcohol informs their student experience more generally. Several of the participants made reference to the extent to which their stance could negatively distinguish them from their peers, hence the importance of recognizing, preparing for and responding to the pressure to conform.

\subsubsection{Coping with the excessive drinking of others}

One major consequence of participating in the student social culture, while being against the excessive consumption of alcohol, is that students often find themselves having to cope with friends and peers who consume alcohol to excess, a challenge that entails the employment of a range of coping strategies. Here Pete discusses the difficult situations that arise when he is around drunken people, including members of his friendship group and people in his wider social world.

Pete: [Whereas] some people you could start a conversation with them and other people... it just wouldn't be very fun hanging around with them when they are drunk. I know when I'm catching a bus to go into town to see my girlfriend, say at 10 o clock on a Saturday night. And there are a lot of Freshers, and if you are stone cold sober and there are a lot of people who are drunk, yeah it's different; it's not a pleasant experience.

Interviewer: So what do you do in that situation?

Pete: I don't know; listen to my MP3 player, read my book.

This excerpt demonstrates Pete's perception that the excessive consumption culture is far-reaching, and potentially impacts on his life in a range of settings (e.g. on the bus going into town). In these situations, his experience moves out of the realm of his chosen social situations (e.g. with friends) into the wider social world where he has less control over his social interactions. Typically, Pete adopts escape-avoidance coping strategies to manage both types of situations (e.g. switching off; wishing the situation were different).

Bob discusses difficulties in forming personal relationships, mainly due to a perceived incompatibility between friends' drunk and sober selves. Here he discusses his relationship with a friend and the effect that alcohol consumption has on their friendship.

Bob: I mean there is a friend. She's one of my closer friends when she's sober. But when she gets drunk, she really, really does go for it and that's difficult because I can't get on with her when she's drunk but she's one of my best friends when she's sober.... I don't [talk about it] because I know that that's my issue not hers or for me that's how it feels. I don't want to impose my ideas of... how people should and shouldn't drink on someone else.... So if I get frustrated with it [his friend's drinking], I know it's not really a healthy 
thing but I tend to just sort of bite my tongue and not say anything about it.

Bob's reticence to challenge the excessive alcohol consumption of his friend is reminiscent of many of the other participants, even those who opt out of drinking for cultural or religious beliefs. Bob copes with this tension through a process of selfcontrol; rather than having potentially difficult discussions, he ensures emotional regulation by keeping his feelings private.

\subsubsection{Roles assumed around drunk friends}

One strategy for coping as an anti-consumer within the drinking culture is to assume a particular role at social events, a form of the planful problem-solving coping strategy. Individuals adopt these roles as a way to alter the potentially stressful social situation.

These roles are primarily functional, involving a specific responsibility, often illustrated by the role of designated driver on evenings out. Other more explicitly caring roles emerge throughout the course of an evening socializing.

Alice: They [friends] would drink and I wouldn't and I was normally the one looking after them and taking them home. And you know, I've always been that way... And they kind of saw that [responsible] role in me, so they were like 'oh Alice will always be there for us', so it... developed like that really.

Alice is particularly adept at ensuring she has a clear purpose within the social group, which includes specific responsibilities as well as a more general responsibility for the well-being of her friends. Alice relishes these roles and enjoys the challenge of adapting to the particular situations she faces. For example, during an exchange year in the United States, Alice confined her involvement in the drinking culture to house parties for under-21s. Despite not drinking herself, Alice would take charge of the door to help warn party organizers of impending police presence.

Assumption of these roles provides a clear purpose for participants' involvement in social events. However, at times assuming a particular role is frustrating, especially when the sense of responsibility for their friends' well-being overshadows their own enjoyment of the social event. In such situations, participants describe the tension between their affiliation and friendship goals (e.g. wanting to be a good friend) and their values relating to personal responsibility (e.g. disapproving of friends' lack of personal control and sense of personal limits).

Kelly: I have no problem with them getting drunk or whatever, but when it gets to the point when they are just a mess and really embarrassing, crying or they ruin my night, they get in such a bad mood, and say 'I want to go home now, I want to go home'.

\section{Discussion}

The study demonstrates that existing frameworks from the voluntary simplicity, brand and product avoidance and coping literature are capable of providing useful theoretical tools for the examination of anti-consumption within the social marketing context. This article identifies some of the implicit tensions of being an anti-consumer in an environment of excessive consumption, and provides examples of how consumers seek to manage these tensions. Perhaps the most important overall learning is that an understanding of the cultural context in which young people exist is critical for the development of policy recommendations or initiatives in this context. Any attempt to tackle problematic alcohol- or indeed drug-consumption necessitates a clear cultural change that challenges the norms and practices of young people as they indulge in what Measham and Brain (2005, p.267) term "leisure time out".

The participants in this study conceptualize their drinking behavior as anti-consumption (despite not adopting this terminology) because their level of alcohol consumption contrasts with, and is against, the perceived norms within their peer group. Therefore, any decision to restrict alcohol intake involves taking some sort of stance, whether implicit or explicit. The practice of being an anti-consumer in this context shares similarities with the practice of voluntary simplification. Voluntary simplifiers operate within the market but to their own guiding principles, hence the continuum of behaviors that voluntary simplification incorporates (Shaw and Newholm, 2002). The anti-consumers in this study could not (or would not) want to leave the student culture entirely. Some participants opt out of certain aspects of this culture but the majority struggle to maintain their anticonsumption stance while remaining part of the student (alcohol) culture. Anti-consumers in this context have to develop ways of managing their position, which is where they draw on various coping strategies, incorporating a somewhat flexible approach within their overall anti-consumption stance.

The article summarizes the antecedents to anti-consumption, and the findings corroborate some of the categories found in Lee and colleagues' brand avoidance framework (Lee and Conroy, 2005; Lee et al., 2009a,b-this issue). The findings suggest that a key reason for avoiding alcohol relates to individuals' strong negative personal experiences with alcohol, either their own or those of close family members. Although these categories overlap with Lee and colleagues' experiential avoidance category, the distinction into two antecedents (personal vs. family experience) provides a deeper understanding of the issues underlying this behavior. The other main antecedent relates to general misgivings in relation to alcohol, specifically the idea that drinking excessively is incongruent with participants' desired self, a form of identity avoidance. Avoiding alcohol for ideological reasons (moral avoidance) is also evident.

Coping theory (Lazarus, 1991) illuminates the ways that anti-excessive consumers cope with the consequences of their choice to reject a dominant consumption culture. A major concern of all participants is managing the social effects of withdrawing from this culture. For example, the typical problemsolving strategies that participants employ (such as assuming the designated driver role in order to have a clear role on a social night out or making planful preparations about how to act in new alcohol dominated social situations) are responses to concerns relating to social situations. When participants describe emotional coping strategies, the strategies they adopt are mainly distancing, escape-avoidance and positive re-appraisal, and again these often relate to the social context (for example the 
use of distancing to manage the social effects of not drinking). Resistance strategies emerge too, mainly focusing on dealing with social situations, for example challenging the stereotypical view some drinkers have of non-drinkers. As Sujan, Sujan, Bettman, and Verhallen (1999) note, consumers who are effective at managing stressful situations tend to use a combination of interpersonal coping strategies, which serve both problemsolving and emotional needs, also the case in this study.

\section{Lessons for social marketing and public policy}

A common focus for public policy in relation to alcohol consumption is on encouraging young people to consume lower levels of alcohol. A number of promotional campaigns (in both the UK and elsewhere) attempt to promote the "drink sensibly" message. Although these campaigns have had some success, this study demonstrates the importance for policy makers and health professionals of appreciating the extent to which drinking sensibly involves going against a dominant culture that welcomes binge drinking. The evidence from this study suggests that attempts to dissuade young people from excessive alcohol consumption are insufficient alone. Showing people how to manage being an anticonsumer in a culture of excessive alcohol consumption is necessary. The participants in this study adopt a range of strategies to help them manage the consequences of their anti-consumption behavior and this information provides a useful starting point from where social marketers can help young people obtain the information, the impetus, and the confidence to adopt alternative subject positions (Nairn et al., 2006) to the dominant binge drinking culture.

Participants' discussions of the antecedents and consequences relevant to their story are often very personal in nature. Building on Measham and Brain's (2005, p276) point that excessive alcohol consumption is an individual behavior that has "enormous public consequences", a useful way forward may be to encourage consumers to take a more global view of the impact of their behaviors. These types of messages could focus on the impact on the economy-e.g. in terms of policing, the health service, the work force-of excessive alcohol consumption, in addition to less tangible societal concerns such as the general well-being of the population. Another useful approach may be to explore ways of encouraging anti-consumers to become more self-confident and vocal about the stance they choose to take (and the reasons why they have adopted this stance) echoing the call for personal responsibility in the UK Government's most recent Alcohol Strategy report (HM Government, 2007).

Consensus exists, in the UK, that challenging problematic drinking will require a cultural change; towards a culture where drinking excessively is not socially acceptable and where "it is socially acceptable for young people to choose not to drink" (HM Government, 2007, p62). Whereas social marketing campaigns have attempted to tackle the former point, the UK Alcohol Strategy (2007) provides little guidance on how to develop a culture where not drinking alcohol is socially acceptable. The findings from the present study suggest that in order to make progress towards a culture that deems non-drinking as socially acceptable, policy makers are going to have to meet the needs of anti-consumers more effectively. In certain contexts (e.g. the student context), alcohol consumption is so embedded in the culture that few anti-consumers are inclined, or able, to carve out a social life distinct from the drinking culture. Although some of the participants in the study organize their own alternative activities, these need to be available on a larger scale. In addition to the huge cultural change involved, making available credible alternatives will involve large sums of money and organization; who or what should assume this responsibility is not clear.

This study did not explore the impact of future possible selves (Markus and Nurius, 1986), even though this was clearly an aspect of some participants' motivations to restrict alcohol consumption (e.g. Pete's academic and career goals). Students could be encouraged to think of university more seriously as an investment for their future. Changes to education policy in the UK may inadvertently help this cause as students (and parents) assume greater responsibility for the payment of tuition fees. One relevant impact would be if students begin to place less emphasis on their social life at university in favor of academic goals. However, additional financial responsibilities could also result in more emphasis on identifying cheaper ways to socialize, and an important factor will be whether the market evolves to accommodate this need for cheaper means to consume (and whether legislation will restrict promotions).

In addition to identifying lessons for social marketing, the marketing and retailing practices around alcohol and the UK drinking culture are important to consider. Over the last ten years, the alcohol industry has re-commodified alcohol in various ways: widening the range of alcohol products on the market (including new highstrength alcohol products); transforming and repositioning alcohol consumption as a lifestyle marker (Brain, 2000) and seeking dramatic changes in drinking establishments and general retail provision (Measham and Brain, 2005). In addition, Measham and Brain (2005) describe the extensive and aggressive use of price promotions and point-of-sale materials in bars, which encourage higher consumption. In relation to the student context, marketing promotions exist that aim to activate specific binge episodes, such as during Freshers' Week, and particular days of the week. Within this context, public policy to support anti-consumers and to encourage less excessive consumption, must recognize and be realistic about the pressures of the marketing context (a key aspect of the social context) within which anti-consumption practices take place.

Social marketing campaigns must address the issues around being an anti-consumer of alcohol. This study found that the main day-to-day challenges of being an anti-consumer emanate from the challenges consumers face in their social lives. The emphasis on the negative health consequences of recent social marketing campaigns is insufficient, since this emphasis fails to deal with the key social and cultural issues for people choosing not to drink.

\section{Limitations}

This article focuses on developing initial understandings about student anti-consumers of alcohol, and a small, in-depth empirical study effectively provides a way of drawing out the main themes. Despite adopting the terminology of anti-consumption, this article attempts to represent clearly the heterogeneity of behaviors present in the sample. A clear limitation is that those who volunteered for 
the study could exhibit particular confidence about the decisions they had made. In writing an article about managing anti-consumption the sampling procedure could have inadvertently selected students who manage very well, albeit using a variety of strategies. However, the aim of this article is not to produce a full descriptive account of the experiences of anti-consumers of alcohol, but rather to shed light on an under-explored topic area.

\section{Future directions}

The opportunities and challenges associated with the practice and management of anti-consumption require further investigation in several respects. Extending this investigation to other research sites, including young people not in education, as well as younger consumers in schools and colleges, would provide a useful starting point. Exploring the perception of anti-consumers by others in their peer group (including self-identified excessive consumers) is another possible avenue for future research. This study is an in-depth investigation of anti-consumers living in a context where excessive consumption is a concern. Future studies could focus on other similar social marketing contexts such as the consumption of unhealthy foods, drugs and smoking. Essentially, future consumer research in other contexts should expand its repertoire to explore anti-consumers as well as consumers. As well as providing a means to understand more about the nature of anti-consumption, a focus on anti-consumers can help shed light on a range of everyday practices

\section{References}

Banister EN, Hogg MK. In: Gilly MC, editor. Mapping the negative self: from 'so not me'...to 'just not me'. Adv Consum ResProvo, UT: Association of Consumer Research; 2001. p. 242-8.

Banister EN, Hogg MK. Negative symbolic consumption and consumer's drivefor self esteem: the case of the fashion industry. Eur J Mark 2004;38(7): 850-68.

Banister EN, Piacentini MG. In: Pechmann C, Price L, editors. Binge drinkingdo they mean us? Living life to the full in students' own words. . Adv Consum ResDuluth, MNL: Association of Consumer Research; 2006. p. 390-8.

Banister E.N., Piacentini M.G. Drunk and (Dis) Orderly: The Role of Alcohol in Supporting Liminality. In: Lee, A.Y. and Soman, D., editors. Adv Consum Res vol. 35. Duluth, MNL: Association of Consumer Research, 2008.

Banister EN, Piacentini MG, Kyriaki-Ioanna B. Discouraging binge drinking among young people: some lessons from light drinkers. Proceedings of the 34th Eur Market Acad Conf Milan; 2005.

Beccaria F, Sande A. Drinking games and the rite of life projects: a social comparison of the meaning and functions of young people's use of alcohol during the rite of passage to adulthood in Italy and Norway. Young Nordic $\mathrm{J}$ Youth Res 2003;11(2):99-119.

Brain K. Youth, Alcohol and the Emergence of the Post-Modern Alcohol Order Occasional PaperLondon: Institute of Alcohol Studies; 2000.

Craig-Lees M. Anti-Consumption: concept clarification and changing consumption behavior. Presentation at the International Centre for Anti-Consumption Research (ICAR), First Symposium on Anti-Consumption. Auckland: University of Auckland; 2006. June.

Craig-Lees M, Hill C. Understanding voluntary simplifiers. Psych Market 2002;19(2):187-210.

D’Alessio M, Baiocco R, Laghi F. The problem of binge drinking among Italian university students: a preliminary investigation. Addict Behav 2006;31(12): 2328-33.

Dalli D, Gistri G, Romani S. Brand dislike: evidence from qualitative research and scale development. Proceedings of the 34th Euro Market Acad Conf Milan; 2005.
Darian JC. In: McAlister L, Rothschild M, editors. Social marketing and consumer behavior: influencing the decision to reduce alcohol consumption. Adv Consum ResProvo, UT: Association of Consumer Research; 1993. p. 413-8.

Etzioni A. Voluntary simplicity: characterization, select psychological implications, and societal consequences. J Econ Psychol 1998;19:619-43.

Folkman S. Dynamics of a stressful encounter: cognitive appraisal, coping and encounter outcomes. J Pers Soc Psychol 1986;50(5):992-1003.

Gill JS. Reported levels of alcohol consumption and binge drinking within the UK undergraduate student population over the last 25 years. Alcohol Alcohol 2002;37(2):109-20.

Godwin BF, Patterson PG, Johnson LW. Emotion, coping and complaining propensity following a dissatisfactory service encounter. J Consum Satisf Dissatisf Complain Behav 1995;8:155-63.

Gofton L. On the town: drink and the 'new lawlessness'. Youth Policy 1990;29:33-9.

HM Government. Safe, Sensible, Social: The Next Steps in the National Alcohol Strategy. London: DH Publications; 2007. June.

Hogg MK, Banister EN. Dislikes, distastes and the undesired self: conceptualizing and exploring the role of the undesired end state in consumer experience. J Market Manag 2001;17:73-104.

Huneke ME. The face of the un-consumer: an empirical examination of the practice of voluntary simplicity in the United States. Psychol Market 2005;22:527-50.

Kozinets RV. Can consumers escape the market? Emancipatory illuminations from Burning Man. J Consum Res 2002;29(1):20-38.

Kuntsche E, Rehm J, Gmel G. Characteristics of binge drinkers in Europe. Soc Sci Med 2004;59:113-27.

Lazarus RS. Emotion and Adaptation. Oxford: Oxford University Press; 1991.

Lazarus RS, Folkman S. Stress, Appraisal and Coping. New York: Springer Publishing Company; 1984.

Lee MSW, Conroy D. Brand Avoidance: the brand as a market-based liability. Proceedings of the 34th Euro Market Acad Conf, Milan; 2005.

Lee MSW, Motion J, Conroy D. Anti-consumption and brand avoidance. J Bus Res 2009;62:169-80 (this issue); [Special Issue on Anti consumption]. doi:10.1016/j.jbusres.2008.01.024.

Lee MSW, Fernandez K, Hyman MR. Anti-consumption: An overview and research agenda. J Bus Res 2009;62:145-7 (this issue); [Special Issue on Anti consumption]. doi:10.1016/j.jbusres.2008.01.021.

Liu X, Kaplan HB. Re-examining gender differences in circumstances surrounding initiation and escalation of binge drinking. Int J Sociol Soc Policy 1996;16(5-6):26-51.

Markus H, Nurius P. Possible selves. Am Psychol 1986;41(9):954-69.

McDonald S, Oates CJ, Young CW, Hwang K. Toward sustainable consumption: researching voluntary simplifiers. Psychol Market 2006;23 (6):515-34.

Measham F. The decline of ecstasy, the rise of 'binge' drinking and the persistence of pleasure. Probat J 2004;41(4):309-26.

Measham F, Brain K. 'Binge' drinking, British alcohol policy and the new culture of intoxication. Crime Media Culture 2005;1:262-83.

Nairn K, Higgins J, Thompson B, Anderson M, Fu N. 'It's just like the teenage stereotype. You go out and drink and stuff': hearing from young people who don't drink. J Youth Stud 2006;9(3):287-304.

Pavis S, Cunningham-Burley S, Amos A. Alcohol consumption and young people. Health Educ Res 1997;12(3):311-22.

Penaloza L, Price LL. In: McAlister L, Rothschild M, editors. Consumer resistance: a conceptual overview. . Adv Consum ResProvo, UT: Association of Consumer Research; 1993. p. 123-8.

Piacentini MG, Banister EN. Getting hammered?: Students coping with alcohol. J Consum Behav Theory Prac 2006;5:145-56 [March-April].

Plant M, Plant M. Binge Britain: the need for courage. Alcoholis 2006;25(3):1.

Poster M. The Question of Agency: Michel de Certeau and the History of Consumerism. Diacritics 1992;22(2):94-107.

Shaw D, Newholm T. Voluntary simplicity and the ethics of consumption. Psychol Market 2002;19(2):167-85.

Spiggle S. Analysis and interpretation of qualitative research in consumer research. J Consum Res 1994;21(3) (Dec):491-503.

Sujan M, Sujan H, Bettman JR, Verhallen TMM. In: Dubois B, Lowrey TM, Shrum LJ, Vanhuele M, editors. Sources of consumers' stress and their coping strategies. Euro Adv Consum ResProvo (UT): Association of Consumer Research; 1999. p. 182-7. 
Thom B, Francome C. Men at risk: risk taking, substance use and gender. Middlesex University; 2001.

Thompson C, Locander W, Pollio H. Putting consumer experience back into consumer research: The philosophy and method of existential-phenomenology. J Consum Res 1989;16:133-46.

Treise D, Wolburg JM, Otnes CC. Understanding the 'social gifts' of drinking rituals: an alternative framework for PSA Developers. J Advert 1997;28(2): $17-31$.

Wachtel PL. Simplifying voluntary simplicity. In: Belk RW, Dholakia N, Venkatesh A, editors. Consumption and marketing: Macrodimensions. Cincinnati, $\mathrm{OH}$ : South-Western College Publishing; 1996. p. 225-31.
Webb E, Ashton CH, Kelly P, Kamal F. Alcohol and drug use in UK university students. Lancet 1996;348:922-5 [Oct 5].

Wechsler H, Lee JE, Kuo M, Seibring M, Nelson TF, Lee H. Trends in college binge drinking during a period of increased prevention efforts: findings from 4 Harvard School of Public Health College Alcohol Study Surveys: 1993-2001. J Amer Coll Health 2002;50:203-17.

Wetherall M, Potter J, Antaki C, editors. Analysing Everyday Explanation. London: Sage Publications Ltd.; 1988. p. 168-83.

Zavestoski S. Guest editorial: anti-consumption attitudes. Psych Market 2002;19(2): $121-6$. 